\title{
Experimental and Numerical Study on the Influence of Corrosion Rate and Shear Span Ratio on Reinforced Concrete Beam
}

\author{
Xiao Guo, ${ }^{1,2,3}$ Hongwei Wang, ${ }^{1}$ Kaizhong Xie $\mathbb{D}^{1,2,3}$ Tuo Shi $\mathbb{D}^{1},{ }^{1}$ and Dan Yu ${ }^{1}$ \\ ${ }^{1}$ College of Civil Engineering and Architecture, Guangxi University, Nanning 530004, China \\ ${ }^{2}$ Key Laboratory of Ministry of Education of Engineering Disaster Prevention and Structural Safety, Guangxi University, \\ Nanning 530004, China \\ ${ }^{3}$ Guangxi Key Laboratory of Engineering Disaster Prevention and Structural Safety, Guangxi University, Nanning 530004, China
}

Correspondence should be addressed to Kaizhong Xie; xiekaizhong@163.com

Received 17 April 2020; Accepted 10 July 2020; Published 8 September 2020

Academic Editor: Aniello Riccio

Copyright (C) 2020 Xiao Guo et al. This is an open access article distributed under the Creative Commons Attribution License, which permits unrestricted use, distribution, and reproduction in any medium, provided the original work is properly cited.

\begin{abstract}
In order to study the influence of corrosion rate and shear span ratio on reinforced concrete beam, a numerical analysis method of corroded reinforced concrete beam was put forward. Bond-slip relationship formula between reinforcement and concrete was suggested. A three-dimensional finite element model of corroded reinforced concrete beam was established. Calculation method of ultimate bearing capacity for reinforced concrete beam was suggested. Ultimate bearing capacity experiment on 14 corroded reinforced concrete beams with different corrosion rates and shear span ratios was carried out. Numerical analysis results and experimental results were compared and analyzed. The results show that, for reinforced concrete beams with different corrosion rates and shear span ratios, load-deflection curve can be divided into elasticity stage and plasticity stage. With the increase of corrosion rate and shear span ratio, ultimate bearing capacity of corroded reinforced concrete beam decreased. When shear span ratio was 3.0, if corrosion rate increased by $1 \%$, experimental value of ultimate bearing capacity decreased by $1.002 \mathrm{kN}$. When shear span ratio was 2.4, if corrosion rate increased by $1 \%$, experimental value of ultimate bearing capacity decreased by $1.849 \mathrm{kN}$. The numerical analysis method put forward in this paper was feasible, and the suggested ultimate bearing capacity calculation method for reinforced concrete beam has a high accuracy.
\end{abstract}

\section{Introduction}

Corrosion is an important disease of reinforced concrete structure; it can weaken performance of steel bars [1] and reduce bond-slip property [2-5] between reinforcement and concrete, which seriously threatens durability and safety of reinforced concrete structures. At present, experiment research is the main method to study corrosion of reinforced concrete structure; it has many advantages, such as high reliability, and it was easier to be recognized. Besides, experiment research method was more consistent with actual corrosion situation. However, there were also many defects regarding experiment research method, such as high cost, unknown factors, and error caused by simplified calculation. Sometimes, results of experiment were wrong because of experiment error. At the same time, numerical analysis method has advantages of low cost, high repeatability, and accuracy, which can solve problems faced by experiment research method; therefore, it was of great scientific significance and engineering value to carry out numerical analysis of corroded reinforced concrete beams.

At present, numerical analysis research on corroded reinforced concrete beam still has various deficiencies; research on the performance of corroded reinforced concrete was mainly based on various assumptions [6]. Study on bond-slip relationship was mainly based on experiment research; bond-slip relationship formula $[7,8]$ was obtained from experimental data by regression analysis. Numerical analysis was carried out based on obtained bond-slip relationship formula. In experimental research, realization of reinforcement's corrosion was carried out through a method of accelerating corrosion by electricity [9]. Many research studies related to corrosion were based on this method [10-12]. This method has 
advantages of simplicity, high efficiency, and so on; however, corrosion of reinforcement produced by this method was often uniform along longitudinal direction of reinforcement, and it was different from actual corrosion situation. At present, there was no report on experimental study of inhomogeneous corrosion along longitudinal direction in corroded reinforced concrete beam. Corresponding to experimental research, in numerical analysis, simulation of corrosion was usually achieved by changing cross-sectional area of corroded steel bars and bond-slip relationship between corroded steel bars and concrete. For interaction mechanism between corroded steel bar and concrete was very complicated, bond-slip relationship currently used in numerical analysis was mainly based on experimental data of small corroded reinforced concrete specimens $[13,14]$; it was simulated by spring element. However, simulation of bond-slip relationship between corroded steel bar and concrete only considers bond-slip relationship parallel to longitudinal direction of reinforcement. Bond-slip perpendicular to longitudinal direction was not considered, and cross section reduction of corroded steel bar was uniform along the longitudinal direction of reinforcement, which was different from the actual corrosion situation. Therefore, in this paper, the influence of corrosion rate and shear span ratio on reinforced concrete beam were studied. Bond-slip relationship formula between reinforcement and concrete was suggested. Three-dimensional finite element model of corroded reinforced concrete beam was established. A calculation method for ultimate bearing capacity of corroded reinforced concrete beam was suggested. An ultimate bearing capacity experiment on 14 corroded reinforced concrete beams with different corrosion rates and shear span ratios was carried out, which can provide useful reference for research of reinforced concrete structure.

\section{Numerical Analysis Method}

2.1. Unit Selection. Corroded reinforced concrete was mainly composed of steel bar, concrete, and bond-slip between steel bar and concrete. In order to reflect mechanical characteristics of structure, selection of units was very important in numerical analysis. Unit type was various according to finite element software used. The large general-purpose finite element software ANSYS was adopted to analyze corroded reinforced concrete beam; it was widely accepted by many engineers and scientific researchers and has a high computational accuracy. Solid65 element was used to simulate concrete. This unit can simulate tensile cracking and compression crushing; it was defined by eight nodes, and each node has three degrees of freedom. Link8 element was used to simulate steel bar. This unit can withstand axial tension except bending moment; it was defined by two nodes, and each node has three degrees of freedom. Combin39 nonlinear spring element was used to simulate bond-slip relationship between steel bar and concrete. This unit has a generalized nonlinear force-deformation curve; it was defined by two nodes, and each node has three degrees of freedom.

2.2. Material Parameters. Value of material parameters in corroded reinforced concrete was very important, which directly affects accuracy of numerical analysis and error size. It was necessary to carry out a thorough study.

2.2.1. Steel Bar. Elastic-full plastic curve was adopted in the stress-strain curve of steel bar as shown in Figure 1. When $\varepsilon_{s} \leq \varepsilon_{y}, \sigma_{s}=E_{s} \varepsilon_{s}$; when $\varepsilon_{y} \leq \varepsilon_{s} \leq \varepsilon_{s, h}, \sigma_{s}=f_{y}$.

During corrosion process of steel bar, with the increase of corrosion rate, strength and ductility of steel bar will be reduced to varying degrees. Xi'an University of Architecture and Technology and many other units have carried out related studies. Corresponding calculation formula was put forward; however, these formulas have not been widely recognized and accepted. In 2007, Xi'an University of Architecture and Technology wrote a standard for durability assessment of concrete structures (CECS 220:2007); it synthesized research results of each unit. Yield strength of corroded steel bar was stipulated, but it recommended that yield strength of corroded steel bar should be determined according to relevant research results when corrosion rate $\eta_{s}>12 \%$. In order to simplify numerical analysis, expression of nominal yield strength and elongation of corroded steel bar was obtained by experiment and finite element simulation of Yuan et al. of China University of Mining and Technology [15-17].

When $\eta_{s} \leq 5 \%$,

$$
\left\{\begin{array}{l}
f_{y s}=\left(1-1.608 \eta_{s}\right) f_{y}, \\
\varepsilon_{u s}=\left(1-2.480 \eta_{s}\right) \varepsilon_{u} .
\end{array}\right.
$$

When $\eta_{s} \geq 5 \%$,

$$
\left\{\begin{array}{l}
f_{y s}=\left(0.962-0.848 \eta_{s}\right) f_{y}, \\
\varepsilon_{u s}=\left(1.088-3.573 \eta_{s}\right) \varepsilon_{u}
\end{array}\right.
$$

2.2.2. Concrete. Hognestad's expression was adopted in the constitutive relation of concrete. Ascending segment of this curve was parabola curve, and downward segment was oblique line.

Expression of ascending segment $\left(\varepsilon \leq \varepsilon_{0}\right)$ is

$$
\sigma=\sigma_{0}\left[2\left(\frac{\varepsilon}{\varepsilon_{0}}\right)-\left(\frac{\varepsilon}{\varepsilon_{0}}\right)^{2}\right] .
$$

Expression of descending segment $\left(\varepsilon_{0} \leq \varepsilon \leq \varepsilon_{\mu}\right)$ is

$$
\sigma=\sigma_{0}\left[1-0.15\left(\frac{\varepsilon-\varepsilon_{0}}{\varepsilon_{\mu}-\varepsilon_{0}}\right)\right] .
$$

Hognestad suggests $\varepsilon_{\mu}=0.0038$ for theoretical analysis, $\varepsilon_{\mu}=0.003$ for design analysis, and $\varepsilon_{0}=2 \sigma_{0} / E_{0}$, where $E_{0}$ is initial modulus of elasticity, and $\sigma_{0}=0.85 f_{c}^{\prime}\left(f_{c}^{\prime}\right.$ is concrete cylindrical compressive strength). The descending segment of concrete stress-strain curve was considered by taking an 


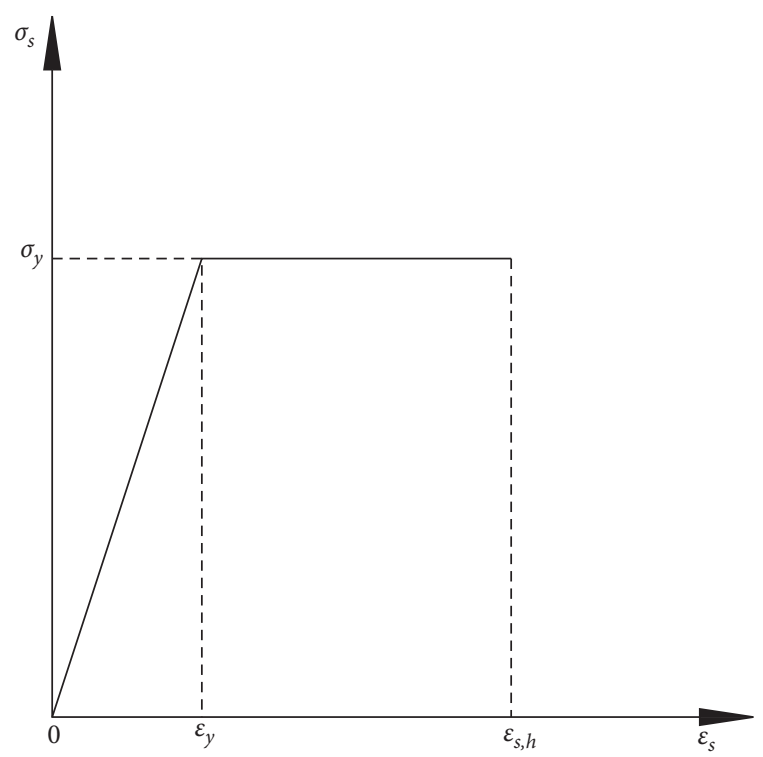

FIGURE 1: Stress-strain curve of steel bar.

oblique line with a $15 \%$ slope. Stress-strain curve of concrete is shown in Figure 2.

2.3. Concrete Cracks. In the analysis of reinforced concrete structure, there were many models to simulate cracks. The three common numerical models were as follows: discrete crack model, distributed crack model, and fracture mechanics model. Distributed crack model has many advantages, such as not needing to redistrict element in calculation, small computation, and being widely used in practice. Crack can be simulated by adjusting stress-strain relationship near integral point. Weak plane was introduced in the direction perpendicular to fracture surface. Shear transfer coefficient $\beta_{t}$ was introduced to express the shear strength reduction coefficient.

Failure criterion of concrete under multiaxial stress was

$$
\frac{F}{f_{c}}-S \geq 0
$$

where $F$ is the function of principal stress state $\left(\sigma_{x p}, \sigma_{y}, \sigma_{z p}\right)$, $S$ is destruction surface, and $f_{c}$ is uniaxial compressive strength. Function $F$ and destruction surface $S$ can be expressed by principal stress $\sigma_{1}, \sigma_{2}, \sigma_{3}\left(\sigma_{1} \geq \sigma_{2} \geq \sigma_{3}\right)$. Concrete damage can be divided into four regions: (1) $0 \geq \sigma_{1} \geq \sigma_{2} \geq \sigma_{3} \quad$ (compression-compression-compression), (2) $\sigma_{1} \geq 0 \geq \sigma_{2} \geq \sigma_{3}$ (tension-compression-compression), (3) $\sigma_{1} \geq \sigma_{2} \geq 0 \geq \sigma_{3}$ (tension-tension- compression), and (4) $\sigma_{1} \geq \sigma_{2} \geq \sigma_{3} \geq 0$ (tension-tension-tension). Function $F$ and damage surface $S$ can be described separately according to different regions; for example, function $F$ can be expressed by four functions $F_{1}, F_{2}, F_{3}, F_{4}$; damage surface $S$ can be described by four functions $S_{1}, S_{2}, S_{3}, S_{4}$. Damage surface described by function $S_{i}(i=1, \ldots, 4)$ was continuous, but for positions where principle stress changes its positive and negative sign, slope of damage surface was discontinuous.

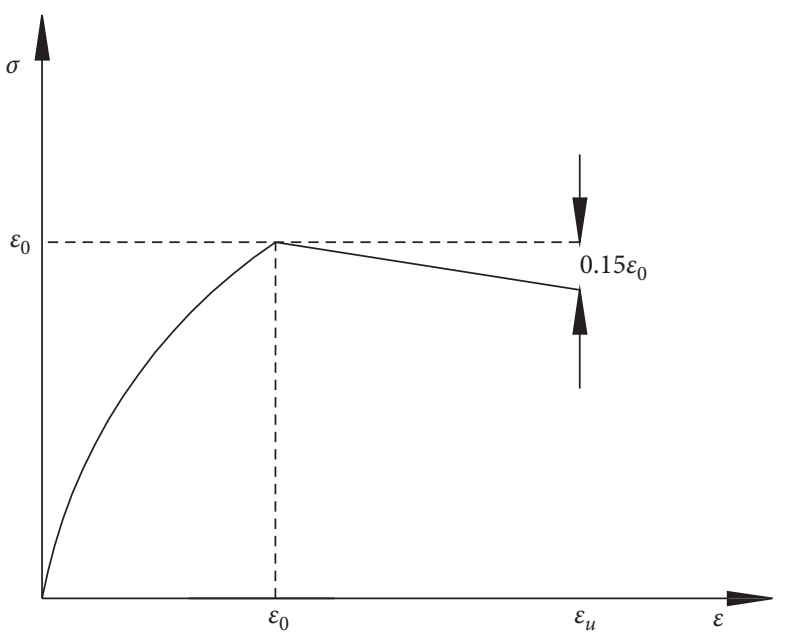

FIGURE 2: Stress-strain curve of concrete.

2.4. Bond-Slip Relationship. Bond-slip relationship between steel bar and concrete was the premise of ensuring normal operation of reinforced concrete members. Establishing local bond stress $(\tau)$-local slip $(s)$ relationship was the key to numerical analysis of reinforced concrete members. Many tests about bond-slippage members have been carried out at home and abroad. It can be divided into three categories according to test purposes: centrality pullout test, beam bonding test, and test of direct measurement of bond and slip values; however, these experimental results cannot reflect the characteristics of local bond stress and local slippage at the interface between steel bar and concrete after corrosion. Bond-slip relationship obtained from short-burial long pullout test can reflect local bond-slip relationship between reinforcement and concrete. It was a reliable mechanical model for reinforced concrete finite element analysis. Therefore, results of existing average bond degradation test were used, the local constitutive relation obtained from test of short-burial long pullout test between steel bar without corrosion and concrete was updated, and the relationship between local bond stress and local slip was obtained, which was at interface between steel bar and concrete.

2.4.1. Local $(\tau-s)$ Constitutive Relationship between Steel Bar without Corrosion and Concrete. Short-burial long drawing test of circular steel bar has been studied [18]. The local $(\tau-s)$ relationship of circular steel bar was obtained, as shown in Figure 3.

$$
\tau_{0}=9.78 \times 10^{2} \cdot s-5.72 \times 10^{4} \cdot s^{2}+8.53 \times 10^{5} \cdot s^{3} .
$$

Short-burial long drawing test for 62 ribbed bars has been studied [19]. The local $(\tau-s)$ relationship of ribbed steel bar was obtained, as shown in Figure 4.

$$
\begin{aligned}
\tau_{0}= & \left(61.5 \cdot s-693 \cdot s^{2}+3.14 \times 10^{3} \cdot s^{3}-0.478 \times 10^{4} \cdot s^{4}\right) \\
& \cdot f_{t, s} \cdot \sqrt{\frac{c}{d}}
\end{aligned}
$$




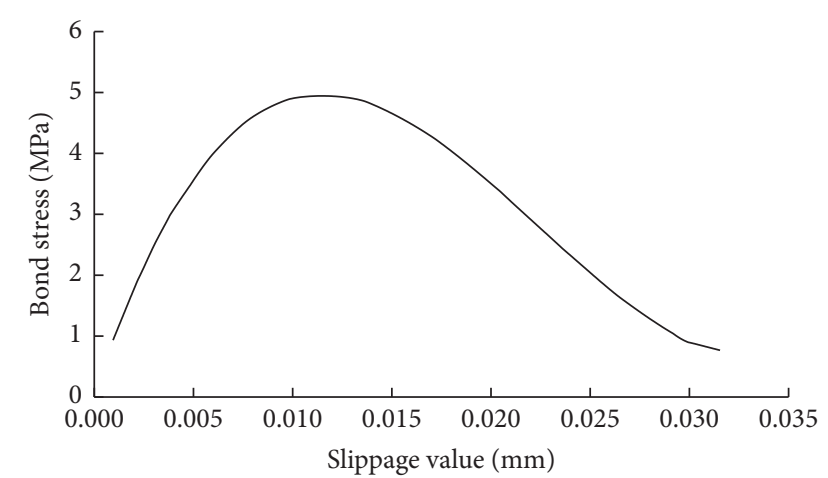

FIGURE 3: Stress-strain relationship between circular steel bar and concrete.

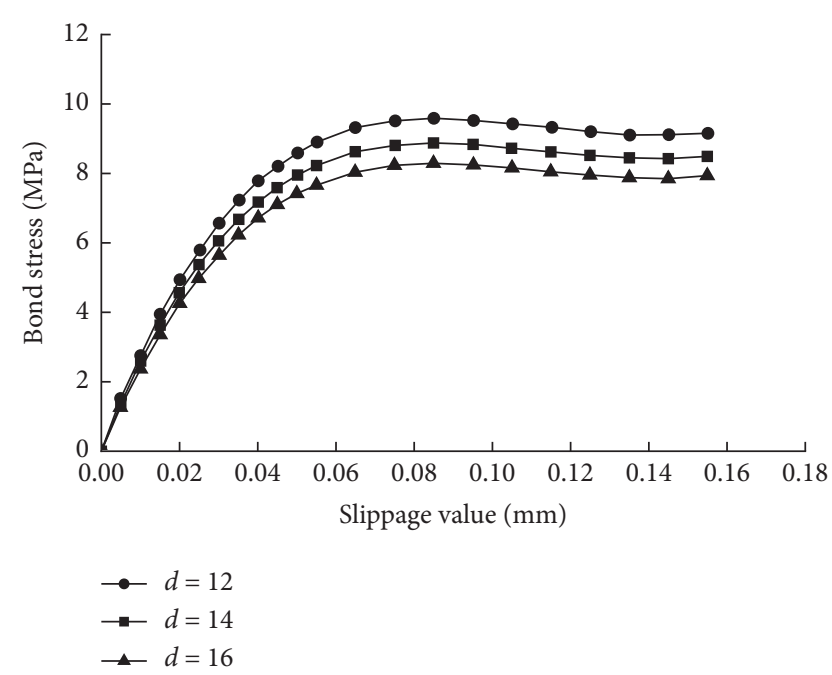

FIgURE 4: Stress-strain relationship between ribbed steel bar and concrete.

As shown in Figures 3 and $4, \tau-s$ relationship between circular steel bar and concrete was obviously different from the $\tau-s$ relationship between ribbed steel bar and concrete. With the increase of slippage value, there was a process from enlargement to reduction for cohesive force between circular steel bar and concrete; however, there was no obvious drop stage or only a slight decrease for cohesive force between ribbed steel bar and concrete. It can be concluded that the influence of steel bar surface shape on the cohesive force between reinforcement and concrete was relatively large, and for ribbed steel bar, the diameter of reinforcement has a significant effect on bond strength. With the increase of diameter and surface area of steel bar, the increase of contact area between steel bar and concrete leads to an increase of bond stress and cohesion strength.

2.4.2. Local $(\tau-s)$ Constitutive Relationship between Corroded Steel Bar and Concrete. The relationship between average bond strength and corrosion rate was obtained from rapid corrosion test [19], as shown in Figure 5. When steel corrosion rate was at a low level, bond strength increased

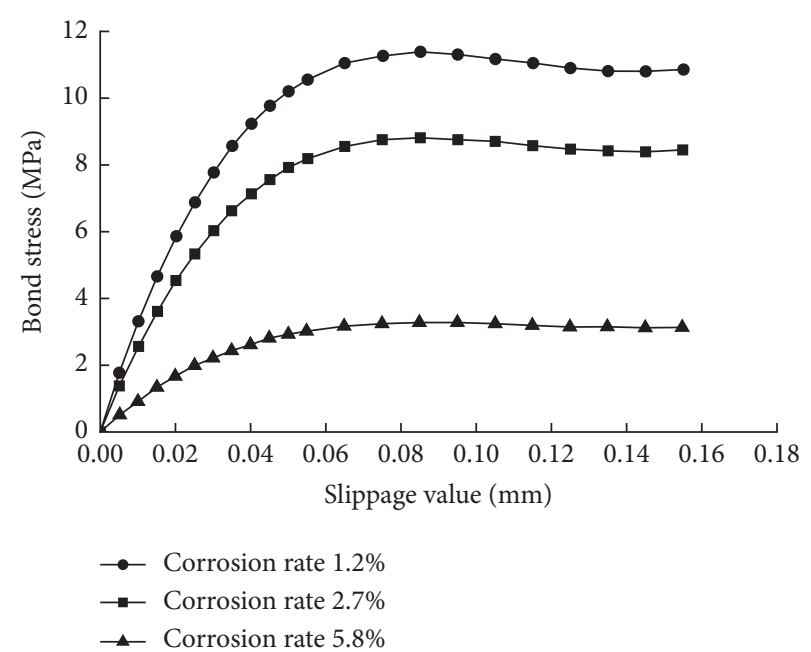

Figure 5: Adhesive-slippage relationship at different corrosion rates.

significantly with the increase of slip. The main reason was that corrosion of steel bar will increase roughness of steel bar surface when corrosion rate was at a low level, thus increasing the bond strength between steel bar and concrete. When corrosion rate continues to increase, bond strength was maintained at a stable stage. Experimental data were shown in Table 1.

For longitudinal steel bar in reinforced concrete, beam was also $\Phi 14$ ribbed steel bar; concrete grade was C30. Material properties in this paper were the same as the material properties in experiment which was carried out by Teng [19] et al.; therefore, calculation formula in the paper of Teng [19] et al. was used to calculate the bearing capacity of corroded reinforced concrete beams in this paper. Data of Table 1 were analyzed by regression analysis. Reduction coefficient expression of bond strength after corrosion was shown as follows:

$$
\beta= \begin{cases}1+0.5625 \eta-0.3375 \eta^{2}+0.055625 \eta^{3}-0.003^{4} & \eta \leq 7 \%, \\ 2.078 \eta^{-1.0369} & \eta>7 \% .\end{cases}
$$

Bond strength expression of corroded reinforced concrete was as follows: $\tau=\beta \cdot \tau_{0}$.

In ANSYS finite element software, simulation of steel corrosion was realized by changing the cross-sectional area of longitudinal steel bar and changing bond-slip relationship between steel bar and concrete. When corrosion rate was measured, yield strength of steel bar and bondslip relationship between steel bar and concrete were calculated according to corrosion rate, and then finite element model was modified. Bond-slip between corroded steel bar and concrete was simulated by Combin 39 element. F-D curve can be clearly defined by a series of discrete points, which were input by real constants and up to 20 data points. In numerical analysis, stiffness coefficient expression of Combin 39 element along longitudinal steel bar direction in reinforced concrete beams without corrosion was as follows: 
TABLE 1: Relationship between corrosion rate and adhesive strength.

\begin{tabular}{|c|c|c|c|c|c|c|c|c|c|}
\hline Corrosion rate (\%) & 0 & 0 & 0 & 0.3 & 0.76 & 0.90 & 1.22 & 1.36 & 1.62 \\
\hline Adhesive strength (MPa) & 16.3 & 15.2 & 16.5 & 19.1 & 21.0 & 21.1 & 19.0 & 20.4 & 18.7 \\
\hline Corrosion rate $(\%)$ & 2.75 & 2.89 & 3.00 & 3.33 & 3.33 & 4.29 & 5.15 & 5.45 & 6.50 \\
\hline Adhesive strength (MPa) & 15.5 & 16.0 & 14.6 & 13.2 & 13.7 & 10.7 & 7.90 & 4.80 & 4.10 \\
\hline
\end{tabular}

$k_{h}=\frac{d_{\tau}}{d_{s}} \cdot \pi \cdot d \cdot l=\left(61.5 s-693 s^{2}+3140 s^{3}-4780 s^{4}\right) f_{t \cdot s} \sqrt{\frac{c}{d}} \pi d l$.

Expression of its F-D curve was as follows:

$$
F=k_{h} D=\left(61.5 D-693 D^{2}+3140 D^{3}-4780 D^{4}\right) f_{t \cdot s} \sqrt{\frac{c}{d}} \pi d l,
$$

where $d$ is diameter of steel bar and $l$ is space of cohesive unit. Expression of F-D curve in corroded reinforced beam can be obtained by multiplying a coefficient $\beta$ on the righthand side of (10). Stiffness coefficient of spring element perpendicular to the direction of longitudinal reinforcement was as follows:

$$
k_{v}=\frac{E \cdot b_{n} \cdot l}{b},
$$

where $E$ is the elastic modulus of concrete, $b_{n}$ is the clear width of concrete at the height of steel bar, and $b$ is the beam width. Expression of F-D curve perpendicular to anchoring direction of spring element was as follows:

$$
F=\int_{0}^{D} k_{v} \mathrm{~d} s=\frac{E \cdot b_{n} \cdot l}{b} \cdot D .
$$

\section{Calculation Method of Ultimate Bearing Capacity}

For ultimate bearing capacity calculation method of reinforced concrete beam without corrosion, calculation of ultimate bearing capacity was mainly based on assumption of plane section, and tensile strength of concrete was not considered. The calculation formula of ultimate bearing capacity for reinforced concrete beam without corrosion was as follows:

$$
M_{u}=\frac{\pi}{4} \sum\left(d_{i}^{2} \cdot f_{y}\right) \cdot h_{0}\left(1-\frac{\pi \sum d_{i}^{2} \cdot f_{y}}{8 \alpha_{1} f_{c} b h_{0}}\right),
$$

where $M_{u}$ is the flexural capacity of reinforced concrete beams without corrosion, $\xi$ is the relative depth of compression zone, $T_{u}$ is the resultant force of longitudinal reinforcement, $d_{i}$ is the diameter of the ith longitudinal reinforcement, $f_{y}$ is the yield strength of longitudinal reinforcement, $\alpha_{1}$ is the ratio between stress of concrete rectangle compression zone and design value of concrete compressive strength, $f_{c}$ is the axial compression strength of concrete, $b$ is the cross section width, and $h_{0}$ is the effective height of cross section.

For ultimate bearing capacity of corroded reinforced concrete beam, formula derivation for its ultimate bearing capacity has been carried out. Obtained formulas for its ultimate bearing capacity were shown in equation(n) and equation(o). Accuracy of equation(n) and equation(o) was verified by test data of 34 test reinforced concrete beams. Average relative error between formula calculation value and experimental value was $6.7 \%$. Formulas for corroded reinforced concrete beam have a high accuracy.

When $\eta \leq 5 \%$,

$$
M_{u}=(1-1.608 \eta)(1-\eta) f_{y} A_{s}\left[h_{0}-\frac{(1-1.608 \eta)(1-\eta) f_{y} A_{s}}{2 \alpha_{1} \cdot f_{c} \cdot b}\right] \text {. }
$$

When $\eta \geq 5 \%$,

$$
\begin{aligned}
M_{u}= & (0.962-0.848 \eta)(1-\eta) f_{y} A_{s} \\
& \cdot\left[h_{0}-\frac{(0.962-0.848 \eta)(1-\eta) f_{y} A_{s}}{2 \alpha_{1} \cdot f_{c} \cdot b}\right],
\end{aligned}
$$

where $M_{u}$ is the flexural capacity of corroded reinforced concrete beams, $f_{y}$ is the yield strength of longitudinal reinforcement, $\xi$ is the relative depth of compression zone, $T_{u}$ is the resultant force of longitudinal reinforcement, $d_{i}$ is the diameter of the ith longitudinal reinforcement, $\alpha_{1}$ is the ratio between stress of concrete rectangle compression zone and design value of concrete compressive strength, $b$ is the cross section width, and $h_{0}$ is the effective height of cross section.

\section{Experimental Verification}

\subsection{Experimental Design and Loading}

4.1.1. Experimental Design. A total of 14 reinforced concrete beams were designed and manufactured. Size and reinforcement ratio of each test beam were the samesize: $1700 \mathrm{~mm} \times 120 \mathrm{~mm} \times 120 \mathrm{~mm}$, reinforcement ratio: $1.5 \%$, and concrete grade: $\mathrm{C} 30$. Shear span ratio was divided into 2.4 (load space $700 \mathrm{~mm}$ ) and 3.0 (load space $500 \mathrm{~mm}$ ), protective layer thickness of concrete was $25 \mathrm{~mm}$, and anchorage length of steel bar was $100 \mathrm{~mm}$. $2 \Phi 14$ longitudinal reinforcement was laid at the bottom of reinforced concrete beam, $2 \Phi 10$ longitudinal reinforcement was laid at the top of reinforced concrete beam, and stirrup was laid as $\Phi 8 @ 150$. Size and reinforcement diagram of test beams is shown in Figure 6. Method of using electricity to accelerate corrosion was adopted; only corrosion of longitudinal steel bar was considered. Accelerated corrosion photos of test beams are shown in Figure 7; design parameters of experimental beams are shown in Table 2. 


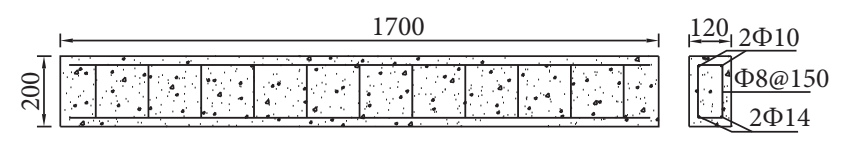

FIGURE 6: Size and reinforcement diagram of experimental beams $(\mathrm{mm})$.

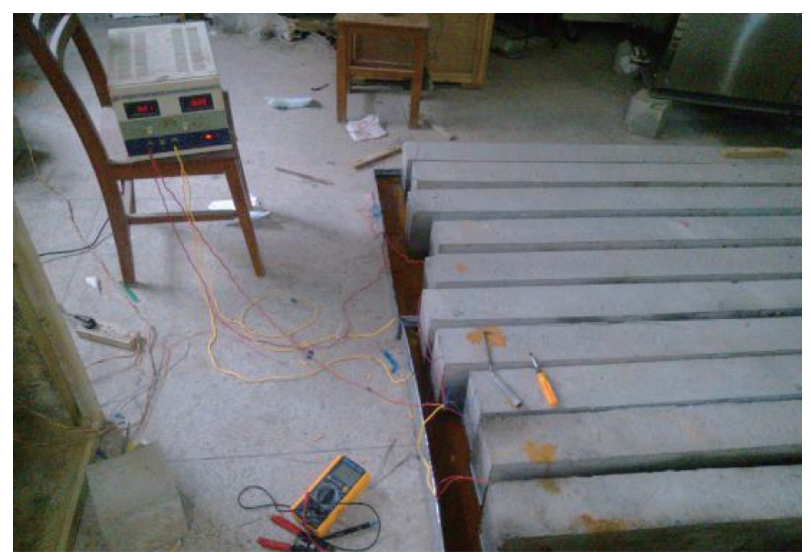

FIGURE 7: Accelerated corrosion photos of test beams.

4.1.2. Experimental Loading. A two-point loading method was adopted in test beams, a $200 \mathrm{KN}$ oil jack was used for loading. In order to prevent concrete from being partially crushed at applied load position, two steel plates of $120 \mathrm{~mm} \times 120 \mathrm{~mm} \times 10 \mathrm{~mm}$ were placed on loading position. Loading diagram and loading photo of test beams are shown in Figures 8 and 9.

4.2. Establishment of Finite Element Model. According to element type selection, material parameter definition, concrete crack simulation, and bondslip simulation between steel bar and concrete in numerical analysis method of corrosion, finite element software ANSYS was used to establish threedimensional finite element model of corroded reinforced concrete beams. Solid65 element was used to simulate concrete, Link 8 element was used to simulated steel bar, and Combin39 nonlinear spring element was used to simulate bondslip relationship between steel bar and concrete. Yield strength $f_{y}$ of longitudinal reinforcement was $335 \mathrm{MPa}$, yield strength $f_{y}$ of stirrup and handling reinforcement was $235 \mathrm{MPa}$, elastic modulus was $2.1 \times 10^{5} \mathrm{MPa}$, Poisson's ratio was 0.3 , and mass density was $7850 \mathrm{~kg} / \mathrm{m}^{3}$. Concrete grade was C30, axial compressive strength was $20.1 \mathrm{MPa}$, uniaxial tensile strength was $2.02 \mathrm{MPa}$, elastic modulus was $3 \times 10^{4} \mathrm{MPa}$, Poisson's ratio was 0.2 , shear transfer coefficient of opening crack and closed crack was 0.5 , and concrete bulk density was $2500 \mathrm{~kg} / \mathrm{m}^{3}$. Finite element model of corroded reinforced concrete beam is shown in Figure 10.

Bearings of test beams were constrained by simple beam support. In order to solve convergence better, crushing option and additional terms of Solid65 element shape function were not considered, release of tensile stress was considered, convergence criterion of force was adopted in solution process, convergence accuracy was 0.05 , and load substep was set to 400 . In order to prevent stress concentration and convergence difficulties, elastic pad or surface load was considered at loading point.

\section{Experimental Results and Discussion}

5.1. Comparison of Load-Deflection Curve. During loading process of test beams, load-deflection curves of test beams were monitored. At the same time, the same load was applied to finite element model of corroded reinforced concrete beams. Load-deflection curves of test beams were extracted. Finite element calculation values of load-deflection curves were compared with experimental values. As the number of test beams was many, limited to article length, only four typical load-deflection curves of test beams BM0-1, BM6-1, BM0-2, and BM6-2 were shown. They are shown in Figures 11-14.

Comparative analysis from Figures 11-14 was made as follows:

(1) For reinforced concrete beams with different corrosion rates, variation trend of measured load-deflection curve was consistent with the variation trend of load-deflection curve obtained from finite element numerical analysis, and measured values were close to those calculated by finite element method

(2) For reinforced concrete beams with different corrosion rates, their load-deflection curves can be divided into two stages: elasticity stage and plasticity stage. At initial loading stage, load-deflection curves basically show a linear variation. Along with the increase of load, tensile cracks were found at the bottom of beams and extended to beam side. Steel bars start to bear force until reaching curve inflection point. Tensile reinforcement begins to yield and enter plastic development stage. At this time, displacement increases sharply when load increases slightly. At last, reinforced concrete beam was destroyed, and ultimate bearing capacity was obtained

(3) Based on comparative analysis of Figures 11 and 12, when corrosion rate increased from $0 \%$ to $14.77 \%$, slope of load-deflection curve of reinforced concrete beam increased at initial stage of loading. Ultimate bearing capacity of test beam decreased from $74.91 \mathrm{kN}$ to $60.11 \mathrm{kN}$. Based on the comparative analysis of Figures 13 and 14, when corrosion rate increased from $0 \%$ to $11.19 \%$, slope of load-deflection curve of reinforced concrete beam increased at the initial stage of loading. Ultimate bearing capacity of test beam decreased from $92.32 \mathrm{kN}$ to $71.63 \mathrm{kN}$. In conclusion, corrosion rate has a great influence on ultimate bearing capacity of reinforced concrete beams and variation speed of load-deflection curve.

5.2. Comparison of Ultimate Bearing Capacity. Ultimate bearing capacity of corroded reinforced concrete beams was calculated and analyzed by ultimate bearing capacity 
TABLE 2: Design parameters of experimental beams.

\begin{tabular}{|c|c|c|c|c|c|c|c|c|}
\hline Number & $\begin{array}{c}\text { Shear span } \\
\text { ratio }\end{array}$ & $\begin{array}{l}\text { Load spacing } \\
(\mathrm{mm})\end{array}$ & $\begin{array}{l}\text { Width } \\
(\mathrm{mm})\end{array}$ & $\begin{array}{c}\text { Height } \\
(\mathrm{mm})\end{array}$ & $\begin{array}{c}\text { Length } \\
(\mathrm{mm})\end{array}$ & $\begin{array}{l}\text { Span } \\
(\mathrm{mm})\end{array}$ & $\begin{array}{c}\text { Thickness of protective } \\
\text { layer }(\mathrm{mm})\end{array}$ & $\begin{array}{c}\text { Design corrosion } \\
\text { rate }(\%)\end{array}$ \\
\hline BM0-1 & 3.0 & 500 & 120 & 200 & 1700 & 1500 & 25 & 0 \\
\hline BM1-1 & 3.0 & 500 & 120 & 200 & 1700 & 1500 & 25 & 2 \\
\hline BM2-1 & 3.0 & 500 & 120 & 200 & 1700 & 1500 & 25 & 5 \\
\hline BM3-1 & 3.0 & 500 & 120 & 200 & 1700 & 1500 & 25 & 8 \\
\hline BM4-1 & 3.0 & 500 & 120 & 200 & 1700 & 1500 & 25 & 10 \\
\hline BM5-1 & 3.0 & 500 & 120 & 200 & 1700 & 1500 & 25 & 12 \\
\hline BM6-1 & 3.0 & 500 & 120 & 200 & 1700 & 1500 & 25 & 15 \\
\hline BM0-2 & 2.4 & 700 & 120 & 200 & 1700 & 1500 & 25 & 0 \\
\hline BM1-2 & 2.4 & 700 & 120 & 200 & 1700 & 1500 & 25 & 2 \\
\hline BM2-2 & 2.4 & 700 & 120 & 200 & 1700 & 1500 & 25 & 5 \\
\hline BM3-2 & 2.4 & 700 & 120 & 200 & 1700 & 1500 & 25 & 8 \\
\hline BM4-2 & 2.4 & 700 & 120 & 200 & 1700 & 1500 & 25 & 10 \\
\hline BM5-2 & 2.4 & 700 & 120 & 200 & 1700 & 1500 & 25 & 12 \\
\hline BM6-2 & 2.4 & 700 & 120 & 200 & 1700 & 1500 & 25 & 15 \\
\hline
\end{tabular}

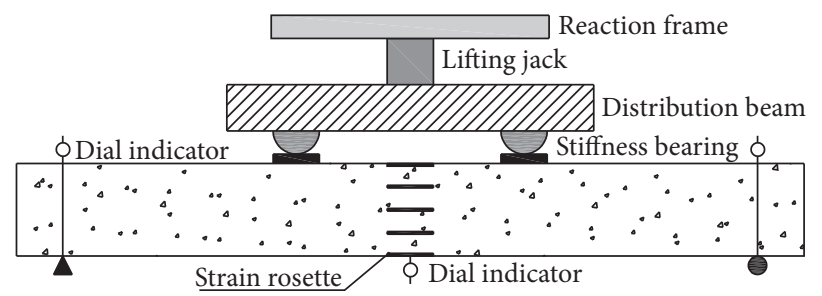

FIGURE 8: Loading diagram of test beam.

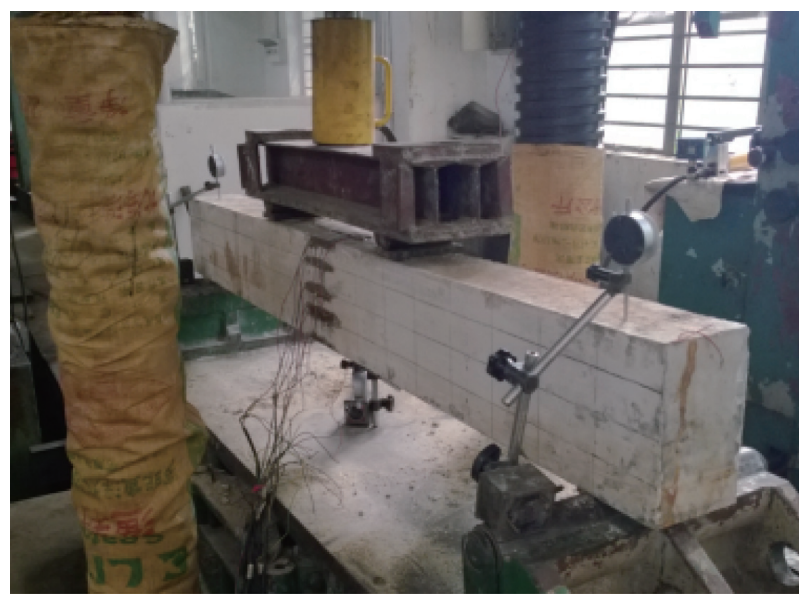

Figure 9: Loading picture of test beam.

calculation formula and numerical analysis method in this paper, and results were compared with experimental results. Comparison of ultimate bearing capacity of RC members with different corrosion rates is shown in Table 3.

Ultimate bearing capacity of reinforced concrete with different corrosion rates and shear span ratios in Table 2 was compared and analyzed as follows:

(1) Whether in group BM1 (shear span ratio 3.0) or group BM2 (shear span ratio 2.4), for variation trend of ultimate bearing capacity in corroded reinforced concrete beams, variation trend of formula calculation values and finite element calculation values

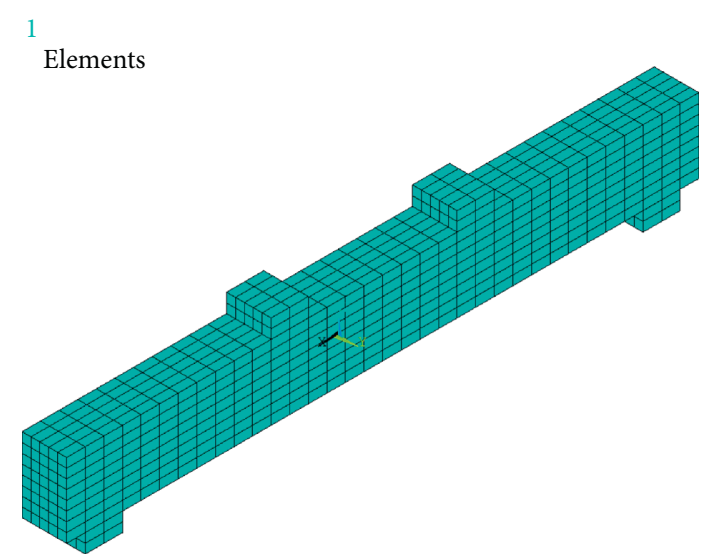

FIGURE 10: Finite element model of corroded reinforced concrete beam.

were consistent with the variation trend of experimental values. Ultimate bearing capacity decreases with the increase of corrosion rate. Finite element calculation values of ultimate bearing capacity were all smaller than the corresponding experimental values, and formula calculation values of ultimate bearing capacity were all larger than the corresponding experimental values

(2) In group BM1 (shear span ratio 3.0), for ultimate bearing capacity of test beams, formula calculation values were $4.53 \%$ larger than experimental values on average, finite element calculation values were 


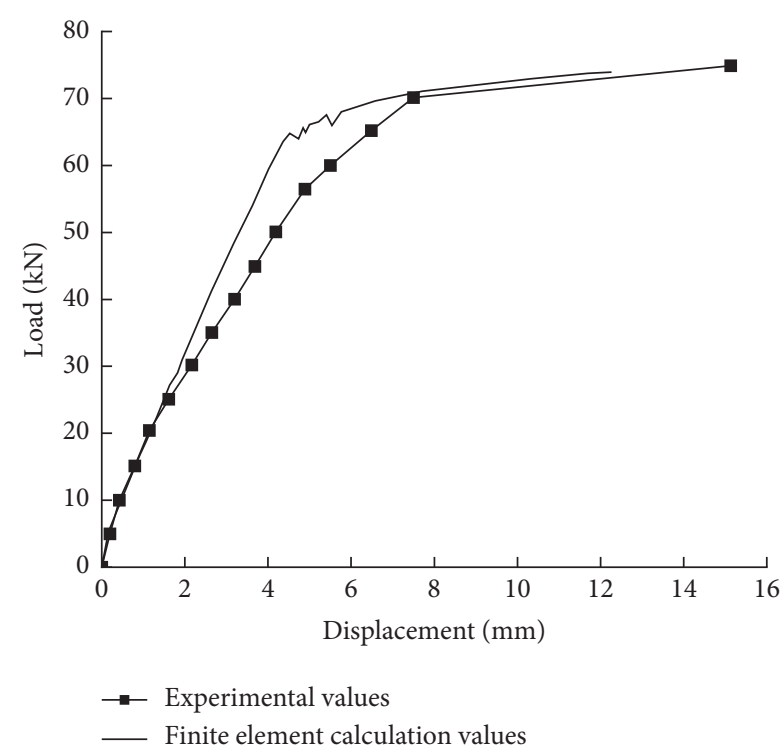

FIGURE 11: Load-deflection curve of test beam BM0-1.

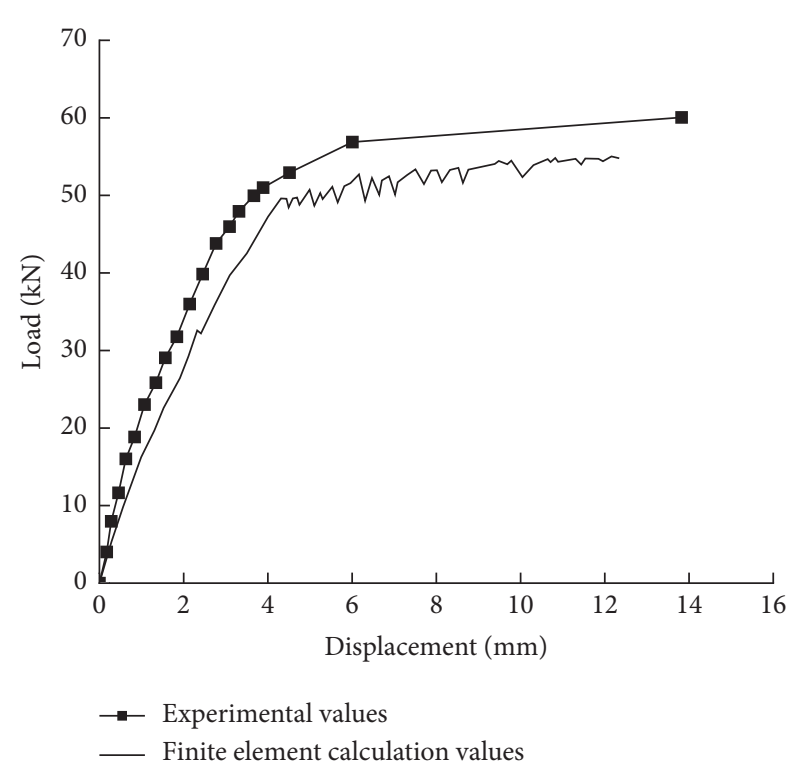

FIgURE 12: Load-deflection curve of test beam BM6-1.

$5.88 \%$ smaller than experimental values on average, and finite element calculation values were $9.96 \%$ smaller than formula calculation values. In group BM2 (shear span ratio 2.4), for ultimate bearing capacity of test beams, formula calculation values were $5.69 \%$ larger than experimental values on average, finite element calculation values were $7.88 \%$ smaller than experimental values on average, and finite element calculation values were $12.77 \%$ smaller than formula calculation values. When shear span ratio decreases, deviation between formula calculation values and experimental values increases, and deviation between finite element

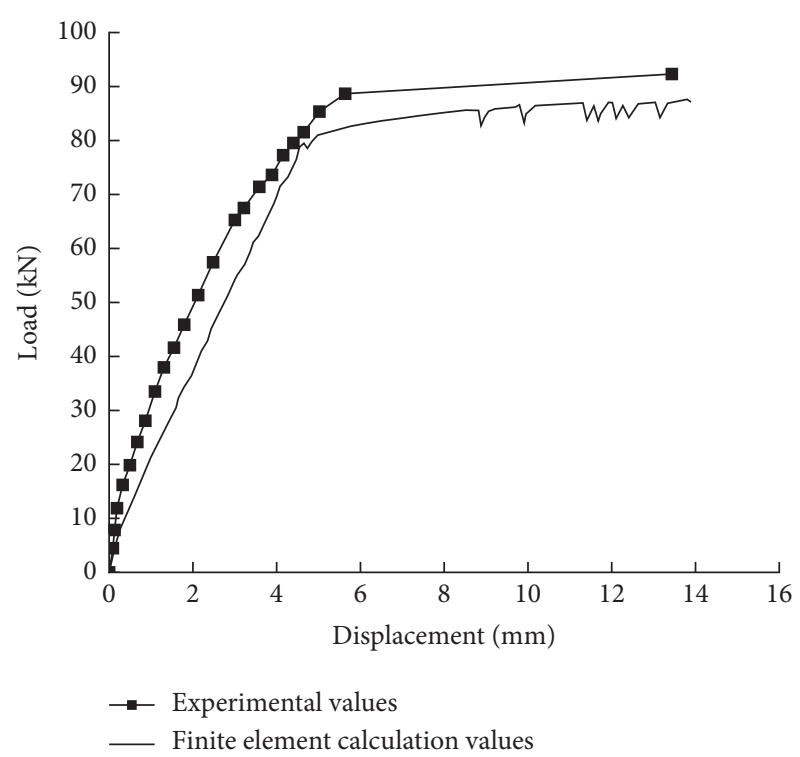

Figure 13: Load-deflection curve of test beam BM0-2.

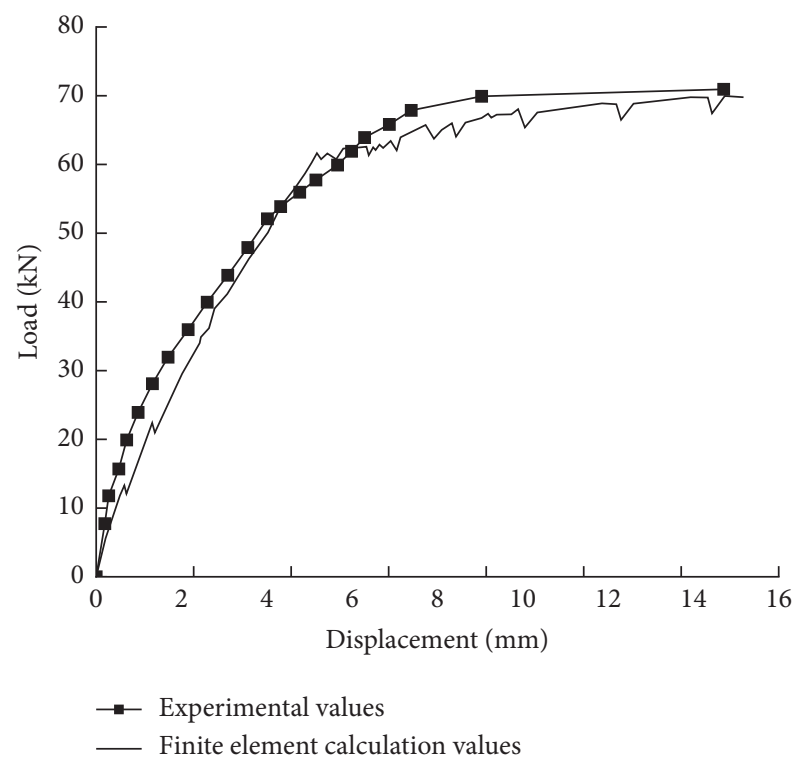

Figure 14: Load-deflection curve of test beam BM6-2.

calculation values with experimental values also increases

(3) In group BM1 (shear span ratio 3.0), corrosion rate increased from $0 \%$ to $14.77 \%$. When corrosion rate increased by $1 \%$, formula calculation value of ultimate bearing capacity decreased by $1.506 \mathrm{kN}$, experimental value of ultimate bearing capacity decreased by $1.002 \mathrm{kN}$, and finite element calculation value of ultimate bearing capacity decreased by $1.268 \mathrm{kN}$. In group BM2 (shear span ratio 2.4), corrosion rate increased from $0 \%$ to $11.19 \%$. When corrosion rate increased by $1 \%$, formula calculation value of ultimate bearing capacity decreased by $1.982 \mathrm{kN}$, experimental value of ultimate bearing 
TABle 3: Comparison of ultimate bearing capacity of RC members with different corrosion rates.

\begin{tabular}{|c|c|c|c|c|c|c|c|}
\hline \multirow[b]{2}{*}{ Number } & \multirow[b]{2}{*}{$\begin{array}{l}\text { Shear span } \\
\quad \text { ratio }\end{array}$} & \multirow[b]{2}{*}{$\begin{array}{l}\text { Load space } \\
\quad(\mathrm{mm})\end{array}$} & \multirow[b]{2}{*}{$\begin{array}{c}\text { Corrosion rate } \\
(\%)\end{array}$} & \multirow[b]{2}{*}{$\begin{array}{c}\text { Thickness of } \\
\text { protective layer }(\mathrm{mm})\end{array}$} & \multicolumn{3}{|c|}{ Ultimate bearing capacity formula $(\mathrm{kN})$} \\
\hline & & & & & $\begin{array}{c}\text { Formula } \\
\text { calculation value }\end{array}$ & $\begin{array}{l}\text { Experimental } \\
\text { value }\end{array}$ & $\begin{array}{l}\text { Finite element } \\
\text { calculation value }\end{array}$ \\
\hline BM0-1 & 3.0 & 500 & 0 & 25 & 82.20 & 74.91 & 73.85 \\
\hline BM1-1 & 3.0 & 500 & 3.12 & 25 & 76.16 & 70.56 & 70.48 \\
\hline BM2-1 & 3.0 & 500 & 5.44 & 25 & 72.00 & 68.30 & 63.58 \\
\hline BM3-1 & 3.0 & 500 & 7.07 & 25 & 69.79 & 67.63 & 63.05 \\
\hline BM4-1 & 3.0 & 500 & 9.88 & 25 & 66.13 & 64.53 & 58.68 \\
\hline BM5-1 & 3.0 & 500 & 10.05 & 25 & 65.91 & 63.85 & 58.36 \\
\hline BM6-1 & 3.0 & 500 & 14.77 & 25 & 59.95 & 60.11 & 55.12 \\
\hline BM0-2 & 2.4 & 700 & 0 & 25 & 102.75 & 92.32 & 87.69 \\
\hline BM1-2 & 2.4 & 700 & 2.11 & 25 & 97.59 & 90.14 & 83.07 \\
\hline BM2-2 & 2.4 & 700 & 5.51 & 25 & 89.82 & 88.37 & 79.95 \\
\hline BM3-2 & 2.4 & 700 & 6.82 & 25 & 87.65 & 86.07 & 78.38 \\
\hline BM4-2 & 2.4 & 700 & 9.08 & 25 & 83.96 & 86.00 & 74.84 \\
\hline BM5-2 & 2.4 & 700 & 9.53 & 25 & 83.23 & 78.03 & 71.19 \\
\hline BM6-2 & 2.4 & 700 & 11.19 & 25 & 80.57 & 71.63 & 70.14 \\
\hline
\end{tabular}

capacity decreased by $1.849 \mathrm{kN}$, and finite element calculation value of ultimate bearing capacity decreased by $1.568 \mathrm{kN}$. When shear span ratio gets smaller, influence of shear span ratio on ultimate bearing capacity of corroded reinforced concrete beams gets bigger.

\section{Conclusions}

Influence of corrosion rate and shear span ratio on reinforced concrete beam was studied in this paper. Main results and conclusions were as follows:

(1) For reinforced concrete beams with different corrosion rates and shear span ratios, load-deflection curve can be divided into elasticity stage and plasticity stage

(2) Corrosion rate and shear span ratio has a great influence on the ultimate bearing capacity of corroded reinforced concrete beams. With the increase of corrosion rate and shear span ratio, ultimate bearing capacity of corroded reinforced concrete beam decreases. When shear span ratio was 3.0, if corrosion rate increased by $1 \%$, experimental value of ultimate bearing capacity decreased by $1.002 \mathrm{kN}$. When shear span ratio was 2.4 , if corrosion rate increased by $1 \%$, experimental value of ultimate bearing capacity decreased by $1.849 \mathrm{kN}$

(3) Numerical analysis method put forward in this paper was feasible; the suggested ultimate bearing capacity calculation method for reinforced concrete beam has a high accuracy, which can provide reference for calculation of corroded reinforced concrete beam.

\section{Data Availability}

The data used to support the findings of this study are available from the corresponding author upon request.

\section{Conflicts of Interest}

The authors declare that they have no conflicts of interest regarding the publication of this paper.

\section{Acknowledgments}

Thanks are due to the National Natural Science Foundation of China (nos. 51868007, 51368005, 51878786, and 51068001) and Guangxi Innovation-Driven Major Projects (Gui KeAA18119055).

\section{References}

[1] J. Z. Sun, Q. Huang, and Y. Ren, "Test for mechanical behavior of steel reinforcing bar after corrosion fatigue," Journal of Harbin Institute of Technology, vol. 48, no. 3, pp. 89-94, 2016.

[2] H. F. Yang, Z. H. Deng, and Y. H. Qin, "Experimental study on bond-slip relationship between corroded rebar and recycled concrete," Engineering Mechanics, vol. 32, no. 10, pp. 114-122, 2015.

[3] Z. H. Chen, D. Y. Tan, Y. Zeng, and W. X. Lin, "Deterioration of reinforced-concrete bond strength due to corrosion," Journal of Chongqing University, vol. 39, no. 1, pp. 79-87, 2016.

[4] C. X. Wang, Y. Wang, J. H. Li, B. Song, and F. B. Cao, "Experimental analysis on bond behavior between recycled concrete and corroded steel bars," Journal of Civil, Architectural \& Environmental Engineering, vol. 38, no. 1, pp. 46-53, 2016.

[5] W. S. Luo, Y. F. Liu, and F. H. Li, "Influence of electrochemical corrosion on reinforced-concrete bond strength," Structural Engineers, vol. 33, no. 4, pp. 47-54, 2017.

[6] K. Yang, X. Y. Guo, J. F. Shao, and Y. F. Fang, "Calculation method for flexural capacity of corroded reinforced concrete beams," Journal of Guangxi University, vol. 43, no. 1, pp. 50-57, 2018.

[7] H. Z. Chang, X. Y. Zheng, and C. Gu, "Effect of corrosion on bonding behavior between rebar and lightweight aggregate concrete," Industrial Construction, vol. 48, no. 1, pp. 122-126, 2018.

[8] L. J. Hou, H. Liu, S. L. Xu, and D. Chen, "Experimental study on bond behavior between corroded rebar and steel fiber 
reinforced concrete," Journal of Building Structures, vol. 38, no. 7, pp. 146-155, 2017.

[9] F. B. Cao, B. B. Ding, C. X. Wang, and Y. Wang, "Experimental and ANSYS analysis of mechanical property on corroded reinforced recycled concrete beams," Journal of Civil, Architectural \& Environmental Engineering, vol. 37, no. S2, pp. 35-40, 2015.

[10] J. Peng, L. Xiao, J. Zhang, C. S. Cai, and L. Wang, "Flexural behavior of corroded HPS beams," Engineering Structures, vol. 195, pp. 274-287, 2019.

[11] L. Xiao, J. Peng, J. Zhang, Y. Ma, and C. S. Cai, "Comparative assessment of mechanical properties of HPS between electrochemical corrosion and spray corrosion," Construction and Building Materials, vol. 237, p. 117735, 2020.

[12] J. X. Peng, H. Tang, L. F. Xiao, X. K. Cheng, and J. R. Zhang, "Experiment and modelling of chloride diffusion and probabilistic analysis of TCI of RC structures," Magazine of Concrete Research, pp. 1-38, 2020.

[13] X. M. Yang, G. J. Sun, Y. L. Chen, and T. Y. Wu, "Analysis on the deterioration of bonding performance between concrete and reinforcement in corroded reinforced concrete beam," Bulletin of the Chinese Ceramic Society, vol. 36, no. 4, pp. 1388-1394, 2017.

[14] M. C. Chen, C. Yang, and K. C. Xu, "Numerical analysis of four-point bending of corroded reinforced concrete beam," Journal of Guangxi University, vol. 42, no. 4, pp. 1217-1226, 2017.

[15] Y. S. Yuan, S. Yu, and F. P. Jia, "Deterioration of bond behavior of corroded reinforced concrete," Industrial Construction, vol. 11, pp. 47-50, 1999.

[16] Y. S. Yuan, F. P. Jia, and Y. Cai, "Deterioration of mechanical behavior of corroded steel bar," Industrial Construction, vol. 30, no. 1, pp. 43-46, 2000.

[17] Y. S. Yuan, F. P. Jia, and Y. Cai, "Structural performance degradation model of corroded reinforced concrete beam," China Civil Engineering Journal, vol. 3, pp. 47-52, 2001.

[18] A. H. Nilson, "Internal measurement of bond slip," ACI Journal, vol. 69, no. 7, pp. 439-441, 1972.

[19] Z. M. Teng and H. Q. Zhang, "Experimental Study of splitting bond failure and development of reinforcing bars in beams," China Civil Engineering Journal, 1989. 